\title{
Influence of a tone's tonal function on temporal change detection
}

\author{
GÉRALDINE LEBRUN-GUILLAUd AND BARBARA TILLMANN \\ CNRS-UMR 5020, Université Claude Bernard Lyon I, Lyon, France \\ and IFR 19, Lyon, France
}

\begin{abstract}
Music cognition research has provided evidence that the tonal function of a musical event influences perception and memory. Our study investigated whether tonal function influences a basic temporal judgment, notably the detection of a temporal change disrupting a sequence's regularity. The sequences consisted of six musical events presented in isochrony (or with the fifth event occurring earlier or later): Three chords (instilling a tonal context) were followed by a tone (repeated three times). The tones fulfilled one of two tonal functions in the tonal context. Participants had to detect whether the sequence contained a temporal change and were not informed about tonal manipulations. Discrimination performance (as measured by $d^{\prime}$ ) showed an influence of tonal function on temporal change detection: Performance was better for the tonic tone (having the most important tonal function in the key) than for the unstable leading tone, the less stable mediant tone, and even than the stable dominant tone. The outcome shows the influence of listeners' tonal knowledge on a perceptual time judgment and suggests that processing of tonal and temporal structures interact at some stage of processing.
\end{abstract}

Music perception requires processing of tones differing in pitch height and duration and occurring at different time points. Depending on the musical context, listeners develop expectations about "what" tone will come next and "when" in time it will occur (see, e.g., Jones \& Boltz, 1989). Tonal and temporal expectations influence perception and memorization of musical sequences even for listeners without explicit musical training (see Bigand \& Poulin-Charronnat, 2006; Krumhansl, 2000; Tillmann, 2005). Our study investigated whether tonal expectations can influence temporal judgments about the regularity of a sequence.

Tonal expectations are based on listeners' implicit knowledge about the Western tonal system and its underlying regularities (i.e., frequencies of co-occurrence, frequencies of occurrence). Nonmusician listeners acquire knowledge about these tonal regularities by mere exposure to musical pieces in everyday life (Francès, 1958; Krumhansl, 1990; Tillmann, Bharucha, \& Bigand, 2000). The tonal system is based on twelve tones $(C, C \sharp / D$ b,$D$, $D^{\sharp} / E b, E, F, F \sharp / G b, G, G \sharp / A b, A, A \sharp / B b, B$ ), with subsets of seven defining keys (e.g., C, D, E, F, G, A, B for C Major). In each key, a hierarchy of functional importance exists between tones and chords. In a major key, for example, the tonic tone (the first degree ${ }^{1} \mathrm{i}$, e.g., $\mathrm{C}$ in $\mathrm{C}$ Major) is at the top of the tonal hierarchy. It is followed in importance by the dominant (the fifth degree v, e.g., G in C Major), the mediant (the third degree iii, e.g., $\mathrm{E}$ in C Major), the other diatonic tones, and finally the leading tone (the seventh degree vii, e.g., B in C Major). In a musical piece, in-key tones are frequently used together and highly referential tonal functions (e.g., the tonic) are used more often than less referential ones (Francès, 1958; Krumhansl, 1990).

Listeners perceive tones at the top of the tonal hierarchy (e.g., tonic) as being more stable and creating less musical tension than other in-key tones with less important tonal functions (see, e.g., Bigand, 1997; Bigand \& Parncutt, 1999; Boltz, 1989b; Krumhansl \& Kessler, 1982). For example, sequences ending on tonic tones are judged as being more complete than sequences ending on other tonal degrees (e.g., Boltz, 1989a; Hébert, Peretz, \& Gagnon, 1995; Tillmann, Bigand, \& Madurell, 1998). On the basis of their tonal knowledge, listeners develop tonal expectations that influence the processing speed of musical events. In the musical priming paradigm (i.e., an indirect investigation method of musical expectations), chord sequences ended either on a stable tonic chord (supposed to be strongly expected) or on a less-stable subdominant chord (i.e., less expected). Listeners make speeded accuracy judgments about a perceptual feature of the last chord (i.e., the target), such as sensory dissonance judgments (e.g., Bigand \& Pineau, 1997) or timbre identification (e.g., Tillmann, Bigand, Escoffier, \& Lalitte, 2006). Result patterns showed the influence of tonal function on speed of chord processing: Response times were faster for the stable, related tonic targets than for the less-related subdominant targets (e.g., Bigand, Poulin, Tillmann, \& D’Adamo, 2003).

In addition to tonal regularities, music is temporally structured. Temporal regularities include the organization

B. Tillmann, barbara.tillmann@olfac.univ-lyon1.fr 
of event-onset intervals leading to a sensation of meter (i.e., regular succession of strong and weak beats superimposed over an isochronous pulse) and rhythmic patterns (i.e., temporal patterns of event-onset intervals, which are perceived against the metrical background). The temporal structures can create temporal accents, occurring at regular intervals, with some tones/chords being perceived as more accented. Listeners are sensitive to temporal regularities and develop temporal expectations about "when" future events will occur (see, e.g., Fraisse, 1974; Jones, 1976; Longuet-Higgins \& Lee, 1984; Povel, 1981). Temporal processing has been studied not only with clicks (e.g., Essens \& Povel, 1985, Experiment 1; Halpern \& Darwin, 1982; Povel \& Essens, 1985) and repeated tones (e.g., Drake \& Botte, 1993; Ehrlé \& Samson, 2005; Essens \& Povel, 1985, Experiments 2 and 3; Hébert \& Cuddy, 2002; Hirsh, Monahan, Grant, \& Singh, 1990; Hyde \& Peretz, 2004), but also with tones in musical contexts (e.g., Drake, 1993; Drake, Penel, \& Bigand, 2000; Jones \& Boltz, 1989; Repp, 1998c). Temporal expectations lead to processing advantages for metrical sequences over nonmetrical (or weakly metrical) ones in production (e.g., Essens \& Povel, 1985; Patel, Iversen, Chen, \& Repp, 2005), perception (e.g., Large \& Jones, 1999; Tillmann \& Lebrun-Guillaud, 2006; Yee, Holleran, \& Jones, 1994), and memory (e.g., Bharucha \& Pryor, 1986; Hébert \& Cuddy, 2002). In isochronous sequences, temporal expectations lead to higher processing accuracy for events occurring (or intervals ending) at expected time points in contrast to events occurring (or intervals ending) earlier or later than expected (e.g., Barnes \& Jones, 2000; Jones, Johnston, \& Puente, 2006; Jones, Moynihan, MacKenzie, \& Puente, 2002; Large \& Jones, 1999; McAuley \& Jones, 2003; Repp, 1992, 1999). Temporal expectations also lead to faster processing for target events occurring on expected time points than those occurring earlier, as well as for events in regular sequences (i.e., with events played in isochrony) than in irregular sequences (i.e., with jittered temporal intervals) (Tillmann \& Lebrun-Guillaud, 2006).

Our present study analyzed the joint processing of tonal function and temporal regularities in musical sequences. Its aim was to investigate whether the detection of a temporal change (disrupting a sequence's isochronous presentation) can be influenced by the tones' tonal function. Sequences consisted of a three-chord context followed by the same tone repeated three times (Figure 1). For regular sequences, the six musical events were presented in an isochronous way with the same interevent intervals. For sequences containing a temporal change, the temporal occurrence of the penultimate tone was manipulated: It could be played earlier or later than expected in the regular context (i.e., creating either negative or positive temporal changes). Participants were asked to indicate whether the sequence contained a temporal change or not. To investigate the influence of tonal function on temporal processing, the tones' tonal function was manipulated (with all tones being in-key events). The three-chord contexts defined harmonic cadences, instilling a specific key, and the three tones had one of two tonal functions in this key. The difference in tonal functions of the tones was decreased over three levels. In Experiment 1, a tone that was strongly related to the context (the tonic tone, the most stable tone in the key) was contrasted with either an unrelated tone (the leading tone, the least stable in-key tone) or a lessrelated tone (the mediant). In Experiment 2, the difference in tonal functions was reduced by opposing the tones of the two highest ranks in the tonal hierarchy: the strongly related tonic tone and the closely related dominant tone. If listeners' tonal expectations influence temporal processing, sensitivity of participants to detect temporal changes (as measured by $d^{\prime}$ ) should be increased for the tonic tone in comparison with the less stable, nontonic tones. In addition, we analyzed the influence of tonal function on listeners' response biases (as measured by $c$ ). On the basis of harmonic priming studies reporting response biases for intonation and asynchrony judgments (Bharucha \& Stoeckig, 1987; Tillmann \& Bharucha, 2002; Tillmann \& Bigand, 2001), we expect that strong tonal oppositions (i.e., tonic vs. leading tone) create stronger response bias differences than finer tonal oppositions (i.e., tonic vs. mediant/dominant). More specifically, the unrelated, unstable tones might create a bias to detect a temporal change, but not (or less strongly) the more stable tones.

\section{EXPERIMENT 1}

\section{Method}

Participants. Sixty-eight students of the University Lyon I participated in Experiment 1. On the basis of the number of years of instrument practice, the 30 participants of Experiment 1A (opposing the tonic to the leading tone) were separated by a median split into 13 moderately experienced listeners (with a mean of 10.2 years of instrument practice) and 17 inexperienced listeners (with a mean of 1.2 years of instrument practice). The 38 participants of Experiment 1B (opposing the tonic to the mediant) were separated by a median split into 18 moderately experienced listeners (with a mean of 6.06 years of instrument practice) and 20 inexperienced listeners (without musical practice).

Material. Sequences consisted of three chords followed by three tones. These tones functioned as either the tonic tone (i), the leading tone (vii), or the mediant tone (iii) (see Figure 1 for an example). The three chords instilled the tonal context and defined one of three harmonic cadences (i.e., VI-V-I, II-V-I, or IV-V-I). Each of the cadences was used for the same number of trials and two different cadences were used for each major key. Twelve major keys and 12 tones were used for Experiment 1A (tonic vs. leading tone), and 9 major keys and 9 tones $(\mathrm{C}, \mathrm{E}, \mathrm{A}, \mathrm{C}, \mathrm{F}, \mathrm{A}, \mathrm{B}, \mathrm{E}, \mathrm{G})$ were used for Experiment $1 \mathrm{~B}$ (tonic vs. mediant). This construction allowed - for each experimental group - the same tone to function as tonic and leading tones or as tonic and mediant tones, depending on the instilled context key. For example, the tone $\mathrm{G}$ functioned as the tonic after a cadence in G Major, but as the leading tone after a cadence of Ab Major, whereas the tone $\mathrm{A} b$ functioned as the tonic after an $\mathrm{A} b$ Major context and as the leading tone after an A Major context. Since repetition effects (i.e., facilitated processing for repeated processing of the same event) have been reported for a variety of materials and tasks, we controlled for tone repetition (i.e., between chords and tones) in order to allow us to interpret facilitated processing for tonic targets in terms of cognitive, tonal expectations. The sequences were constructed in such a way that the prior occurrence of the tones (at the same pitch height) in the chord contexts favored the unrelated, nontonic conditions: Over 24 trials, the leading tone occurred 16 times and the tonic 15 times in the chord contexts (Experiment 1A); over 18 trials, the mediant tone occurred 16 times and the tonic 13 times (Experiment 1B). The pitch heights of tonic, mediant, and leading tones were in the range of the pitch height defined by the tones of the chords. 
A

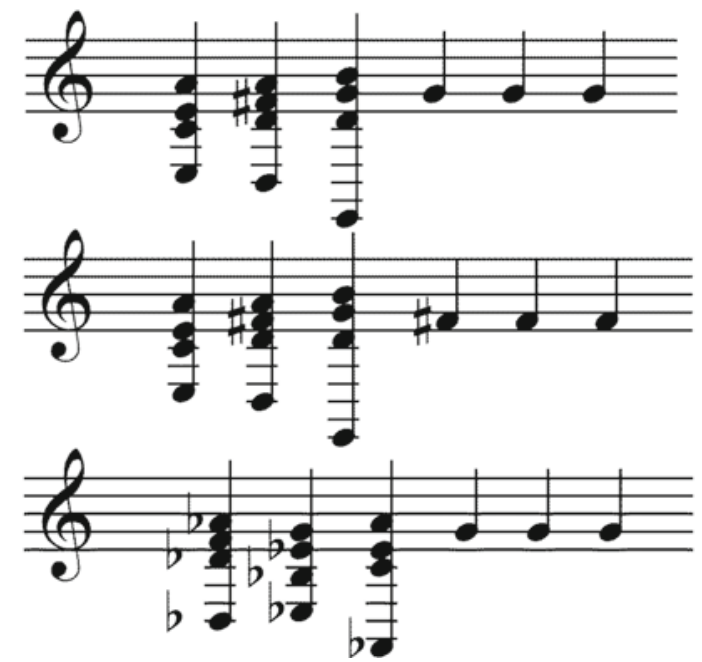

Chord Context

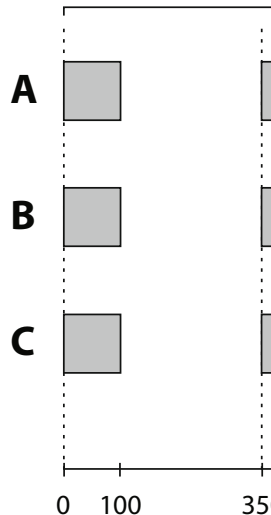

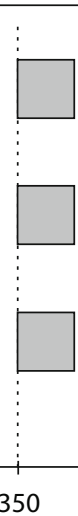

Figure 1.Top: An example of experimental sequences for (A) the strongly related condition with the three tones functioning as the tonic in the context of G Major; (B) the unrelated condition, with the same tonal context as that in (A), but followed by three tones functioning as the leading tone; and (C) the unrelated condition, with the same three tones as those in (A), but functioning as the leading tone in the chord context of Ab Major. Bottom: Schematic representation of the temporal manipulations, sequences with the second tone played (from top to bottom row) on time, earlier, and later.

Each chord and each tone was played for $100 \mathrm{msec}$. Standard interchord intervals (ICIs) and intertone intervals (ITIs) were $350 \mathrm{msec}$. For isochronous sequences, the second tone (i.e., fifth event in the overall sequence) was played with the standard ITI of $350 \mathrm{msec}$ (i.e., on time). For sequences containing a temporal change, the second tone was played either earlier with an ITI of 320 or $310 \mathrm{msec}$ (standard ITI $-30 \mathrm{msec}$; standard ITI $-40 \mathrm{msec}$, defining the negative change) or later with an ITI of 380 or $390 \mathrm{msec}$ (standard ITI + $30 \mathrm{msec}$; standard ITI $+40 \mathrm{msec}$, defining the positive change) (see Figure 1, bottom). The temporal change thus corresponded to a displacement of one event, with the event following the temporal change remaining in its original temporal position (i.e., creating a local anisochrony; see Ehrlé \& Samson, 2005). Sound examples are available at olfac.univ-lyon 1.fr/bt-sound.html.

Apparatus. The sequences were constructed with Digital Performer 3.01 software (Mark of the Unicorn) and played with an acoustic grand piano sound (reference XG001) that was produced by a Yamaha SO3 synthesizer. The synthesizer was controlled through a MIDI interface by a Macintosh computer running Digital Performer 3.01 software. The sequences were recorded by SoundEdit 16 Software (Macromedia), and the experiment was run on PsyScope 1.2.5 PPC software (Cohen, MacWhinney, Flatt, \& Provost, 1993).
Procedure. Participants were asked to press a "yes" button when they detected a temporal change (they were informed of the location of the possible change) and a "no" button when they were unable to detect a temporal change in the overall sequence (adapted from Hyde \& Peretz, 2004). Before starting the experiment, participants listened to six examples and were allowed to listen to the examples until they were able to detect the temporal changes. These examples consisted of two sequences without temporal changes (i.e., one with tonic targets and one with nontonic targets) and of four sequences with temporal changes (i.e., \pm 30 to $\pm 40 \mathrm{msec}$, with two tonic and two nontonic targets). In the experimental phase, trials were presented in random order for each participant. After each response, a 250-msec noise mask was presented to erase the sensory memory buffer and avoid tonal carryover effects between trials. No response feedback was given. Pressing the space bar on the computer keyboard started the next trial. Short breaks of $10 \mathrm{sec}$ were imposed during the experimental session after a subset of 24 trials, and participants had the option of taking additional breaks by waiting to initiate the next trial. The duration of the experiment was about 30-40 min.

Design. The within-participants factors were tonal function (tonic/nontonic), direction of temporal change (negative change/ 
positive change), and extent of temporal change ( $30 \mathrm{msec} / 40 \mathrm{msec})$. The between-participants factors were musical expertise (moderately experienced/inexperienced) and type of nontonic tone (leading tone/mediant), which was tested with the two experimental groups (Experiments 1A and 1B).

For the leading-tone group (Experiment 1A), 384 trials were constructed: 192 without temporal change ( 96 with the tonic, 96 with the leading tone) and 192 with temporal change (48 trials for each of the temporal changes $( \pm 30 \mathrm{msec} ; \pm 40 \mathrm{msec})$, with 24 being presented with the tonic and 24 being presented with the leading tone). However, because of a programming error, three cadences (two cadences in B bajor and one cadence in D Major) were not presented, thus reducing the number of trials to 336 (i.e., the missing trials equally affected the different conditions). For the mediant group (Experiment 1B), each participant judged 288 sequences: 144 without temporal change (72 with the tonic, 72 with the mediant) and 144 with temporal change ( 36 trials for each of the temporal changes, with 18 being presented with the tonic and 18 with the mediant).

Data analyses. Detection performance was analyzed with signal detection theory calculating for each participant, and for each condition discrimination sensitivity with $d^{\prime}$ and response bias with $c .^{2}$ For each participant, these analyses were based on hits (i.e., correct change detection) for each of the temporal changes $( \pm 30 \mathrm{msec}$; $\pm 40 \mathrm{msec}$ ) separating tonic and nontonic trials (i.e., leading tone, mediant) and on false alarms separating tonic and nontonic trials. We analyzed $d^{\prime}$ and $c$ by two ANOVAs with tonal function, direction of temporal change, and extent of temporal change as withinparticipants factors, and musical expertise and type of nontonic tone as between-participants factors.

\section{Results}

For $d^{\prime}$ (Figure 2, left), the main effect of tonal function was significant $\left[F(1,64)=13.45, M S_{\mathrm{e}}=0.26, p<.001\right]$. Participants were more sensitive at detecting the temporal change when the three tones functioned as the tonic than when they functioned as a nontonic tone. The main effect of direction of temporal change was also significant
$\left[F(1,64)=110.73, M S_{\mathrm{e}}=0.57, p<.0001\right]$, as was the main effect of extent of temporal change $[F(1,64)=379.61$, $\left.M S_{\mathrm{e}}=0.15, p<.0001\right]$ and their interaction $[F(1,64)=$ $\left.52.17, M S_{\mathrm{e}}=0.16, p<.0001\right]$. Performance was better for positive changes than for negative changes and for 40 -msec changes than for 30 -msec changes. The difference in sensitivity between positive and negative changes was less pronounced for the change of $40 \mathrm{msec}$ than for the change of $30 \mathrm{msec}$. No other significant effects were observed.

For $c$ (Figure 3, left), the main effect of tonal function was significant $\left[F(1,64)=20.09, M S_{\mathrm{e}}=0.11, p<\right.$ .0001]. Participants tended to respond more strongly, "No, there was no change" when the tones functioned as the tonic tone than when they functioned as a nontonic tone. The interaction between tonal function and type of nontonic tone was significant $\left[F(1,64)=5.80, M S_{\mathrm{e}}=0.11\right.$, $p<.05]$. The difference in response bias between the two tested tonal functions was stronger for the opposition between tonic and leading tone [Experiment 1A, $F(1,64)=$ $21.10, p<.0001]$ than for that between tonic and mediant (Experiment 1B, n.s.). Moreover, only for leading tones (notably for 40-msec changes) did participants tend to respond "Yes, there was a change" (as indicated by the negative $c$ values). In addition, the main effects of direction of temporal change $\left[F(1,64)=94.68, M S_{\mathrm{e}}=0.16, p<\right.$ $.0001]$ and extent of temporal change $[F(1,64)=462.47$, $\left.M S_{\mathrm{e}}=0.03, p<.0001\right]$ were significant, as was their interaction $\left[F(1,64)=44.92, M S_{\mathrm{e}}=0.04, p<.0001\right]$. Participants' bias to respond "No, there was no change" was more important for $30 \mathrm{msec}$ than for $40 \mathrm{msec}$, and was more important for negative than for positive changesparticularly for the small temporal changes (i.e., $30 \mathrm{msec}$ ). No other effects were significant.

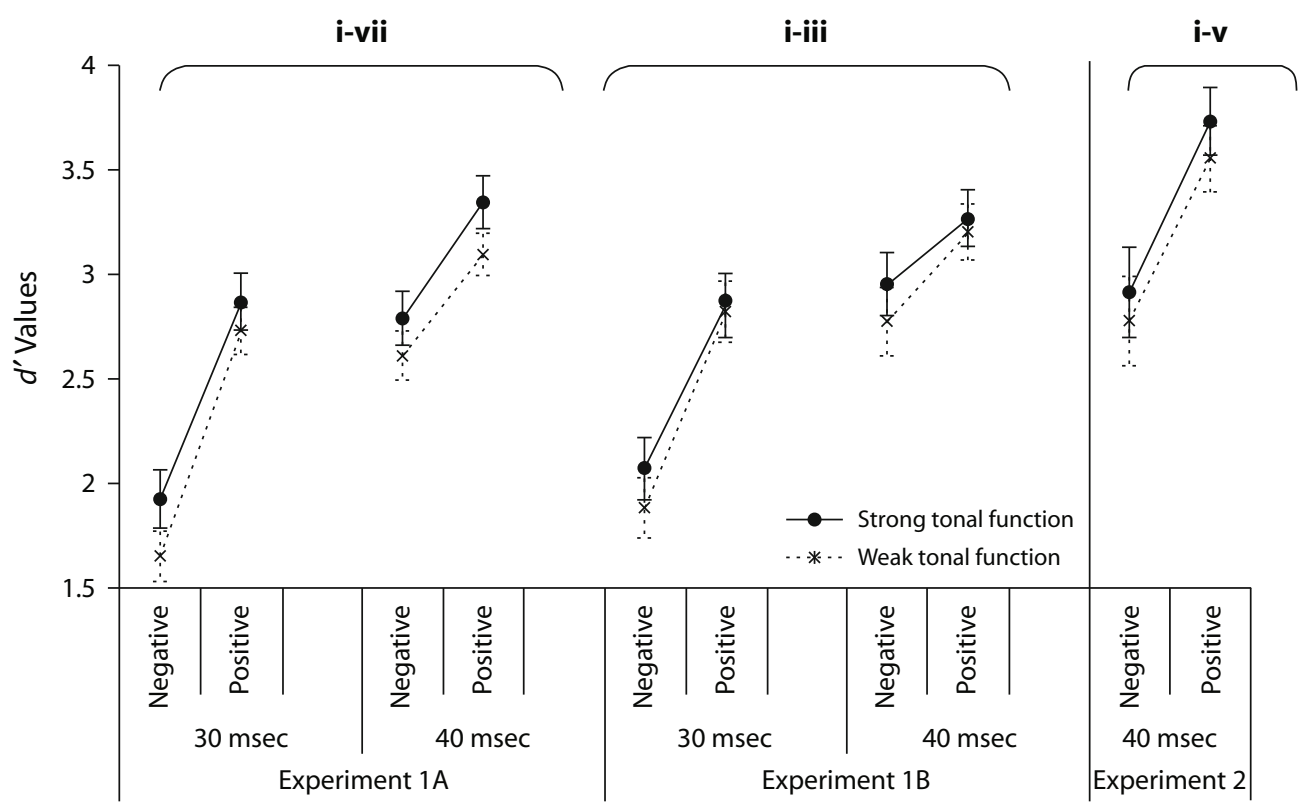

Figure 2. $d^{\prime}$ data pattern of Experiments 1 and 2 averaged over participants and sequence set, presented as a function of the direction of temporal change (negative or positive), extent of temporal change ( $30 \mathrm{msec}$ [Experiment 1] or $40 \mathrm{msec}$ [Experiments 1 and 2]), and tonal function (tonic i vs. leading tone vii [Experiment 1A], mediant iii [Experiment 1B], or dominant v [Experiment 2]). 


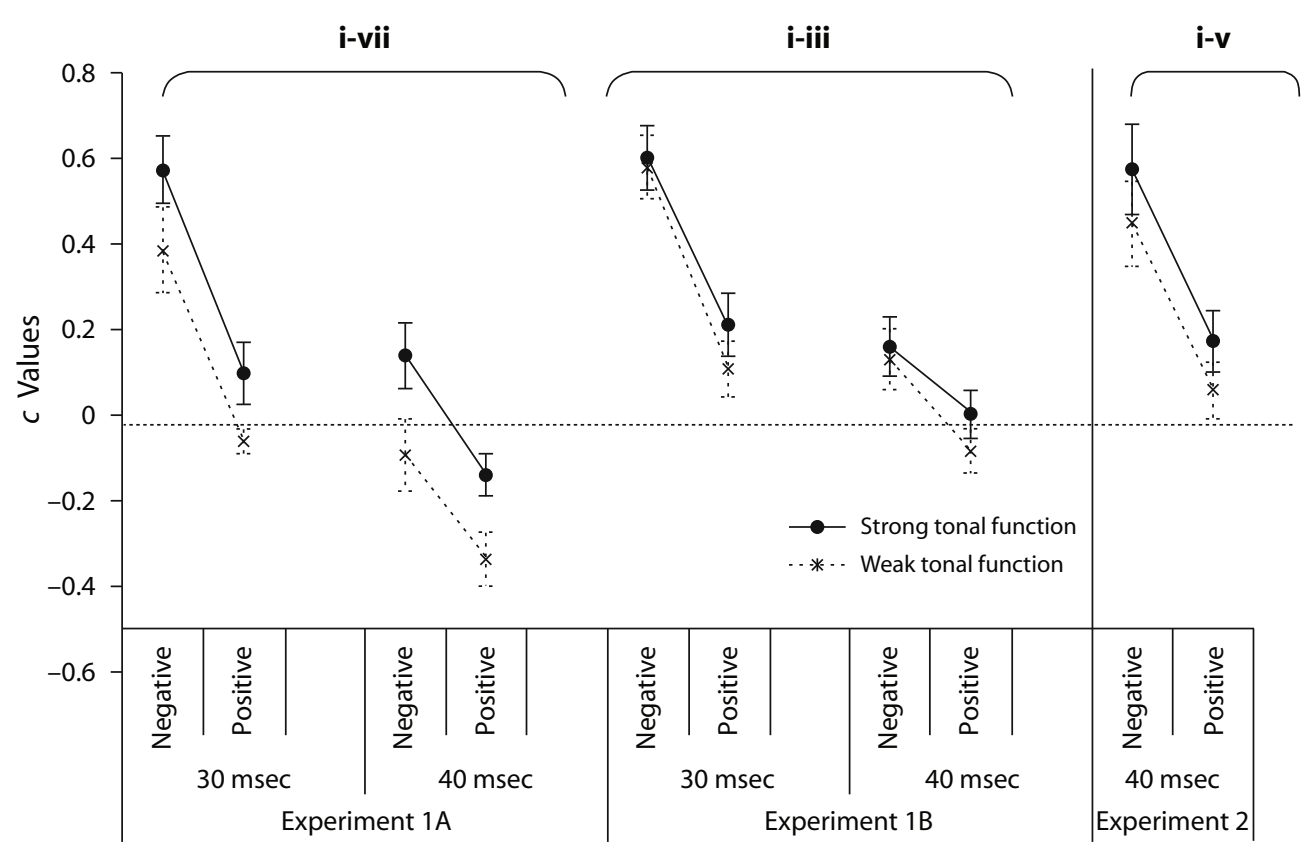

Figure 3. $c$ data pattern of Experiments 1 and 2 averaged over participants and sequence set, presented as a function of direction of temporal change (negative or positive), extent of temporal change ( $30 \mathrm{msec}$ [Experiment 1] or $40 \mathrm{msec}$ [Experiments 1 and 2]), and tonal function (tonic i vs. leading tone vii [Experiment 1A], mediant iii [Experiment 1B]), or dominant $\mathrm{v}$ [Experiment 2]). Positive values of $c$ correspond to a response bias indicating that participants tend to respond "No, there was no change," and negative values indicating the bias to respond "Yes, there was a change."

\section{Discussion}

The influence of tonal function on temporal change detection was investigated with a strong tonal opposition (Experiment 1A) and a subtler one (Experiment 1B). The related tone occupied the highest position in the in-key hierarchy of tones (i.e., the tonic) and the less-related ones occupied either the lowest (seventh) position (i.e., the leading tone) or the third position (i.e., the mediant). Listeners' sensitivities to detect the temporal change (as measured by $d^{\prime}$ ) were stronger for the tonic tone than for the nontonic tones (i.e., leading tone and mediant). This influence of tonal function suggests that tonal expectations also influence temporal processing, with more accurate processing for the tonic tone.

Tonal function also influenced listeners' response biases (as measured by $c$ ): Listeners had a stronger tendency to respond "No, there was no change" for tonic tones than for nontonic tones, for which the bias even became negative ("Yes, there was a change"). The weakest tonal function (the leading tone) more strongly influenced listeners' response biases than did the mediant tone. The leading tone might sound particularly unstable in the tonal context and leads not only to an increased response bias, but (for the 40-msec trials) also to a negative bias. Even if listeners are not informed about the tonal manipulations, they might have perceived the strong opposition between tonic and leading tone, which influenced their response biases. This explicit perception seems to be reduced for the finer tonal differences. In contrast to response bias, the strength of opposition in tonal functions did not influence listeners' sensitivities to detect temporal changes: The difference between nontonic and tonic tones was not stronger for the comparison involving the leading tone than that involving the mediant.

In addition to the effect of tonal function, Experiment 1 showed better discrimination for stronger temporal changes $(40 \mathrm{msec})$ as well as for positive changes, and the difference between positive and negative changes was more pronounced for smaller changes $(30 \mathrm{msec})$. The asymmetry of temporal change direction (which will be further discussed in the General Discussion) might be enhanced, because overall smaller changes were more difficult to detect than 40-msec changes.

\section{EXPERIMENT 2}

Experiment 2 reduced the opposition of tonal functions by contrasting the two tones occupying the first two ranks in tonal hierarchy: the strongly related tonic versus the closely related dominant. The aim was to investigate whether listeners perceive this fine difference in tonal functions and whether it influences temporal processing. Furthermore, we expected that the response bias should be less negative (or even become positive) for these stable dominant tones, since their stronger stability should decrease participants' conscious detections of the manipulated tonal function.

\section{Method}

Participants. Twenty-nine students from universities in Lyon participated in Experiment 2 (mean age $=21.8$ years). None had participated in Experiment 1. On the basis of the number of years of instrument practice, they were separated by a median split into a group of 18 moderately experienced listeners (with a mean of 
6.79 years of instrument practice) and a group of 20 inexperienced listeners (without musical practice)

Material. The material was the same as that described in Experiment 1 (using the twelve major keys), except for the tonal functions and the use of only the temporal change of $40 \mathrm{msec}$ (allowing us to increase the number of trials per condition). The three tones functioned as either the tonic tone (i) or the dominant tone (v) in the tonal context, defining strongly related and closely related conditions, respectively. The sequences were constructed in such a way that the repetition of the tones (at the same pitch height) in the context favored the closely related condition: Over the 24 sequences, the dominant tone occurred 33 times and the tonic tone occurred 25 times in the chord contexts. Pitch heights of tonic and dominant were in the pitch height range defined by tones of the context chords. After half of the cadences, the tonic was higher in pitch height than the dominant tone and in the other half of the sequences, it was the reverse.

Apparatus. The material was constructed with Digital Performer 3.01 software, and the MIDI files were transformed into sound files using the acoustic piano sound The Grand (Steinberg) with Cubase software (Steinberg). Chord contexts and tones were recorded separately and then combined into the sequences using the digital sound software SoundEdit. The experiment was run on PsyScope 1.2.5 PPC software (Cohen et al., 1993).

Procedure. The procedure was the same as that described in Experiment 1 . Because only the extent of $40 \mathrm{msec}$ was used, all trials were presented twice. The duration of the experiment was about 40 min containing two blocks separated by an additional short break.

Design. The within-participants factors were tonal function (tonic/dominant) and direction of temporal change (negative change/positive change). Each participant judged 384 sequences presented in random orders in two blocks: 192 without temporal change (96 with the tonic, 96 with the dominant tone) and 192 with temporal change ( 96 trials for each of the temporal changes [ $\pm 40 \mathrm{msec}$, with 48 being presented with the tonic and 48 with the dominant).

Data analyses. As in Experiment 1, detection performance was analyzed with signal detection theory calculating for each participant and for each condition discrimination sensitivity with $d^{\prime}$, and response bias with $c$. Two ANOVAs analyzed $d^{\prime}$ and $c$, with tonal function (tonic/dominant) and direction of temporal change (negative/positive) as within-participants factors and musical expertise as a between-participants factor.

\section{Results}

For $d^{\prime}$ (Figure 2, right), the main effect of tonal function was significant $\left[F(1,27)=5.53, M S_{\mathrm{e}}=0.57, p<.05\right]$. Participants were more sensitive at detecting the temporal change when the tones functioned as the tonic than as the dominant. The main effect of direction of temporal change was also significant $\left[F(1,27)=32.03, M S_{\mathrm{e}}=0.53, p<\right.$ $.0001]$, with better sensitivity for positive than for negative changes. In addition, the main effect of musical expertise was significant $\left[F(1,27)=4.71, M S_{\mathrm{e}}=2.99, p<.05\right]$. The more experienced participants $\left(d^{\prime}=3.6\right)$ were more sensitive at detecting temporal changes than the inexperienced ones $\left(d^{\prime}=2.9\right)$. No other effects were significant.

For $c$ (Figure 3, right), the main effect of tonal function was significant $\left[F(1,27)=7.84, M S_{\mathrm{e}}=0.05, p<.01\right]$; participants tended more strongly to respond "No, there was no change" for tonic tones than for dominant tones. The main effect of direction of temporal change was significant $\left[F(1,27)=30.83, M S_{\mathrm{e}}=0.15, p<.0001\right]$, with a more important tendency to respond "No, there was no change" for negative temporal changes. No other effects were significant.

\section{Discussion}

Despite the subtle opposition in tonal functions, Experiment 2 revealed listeners' stronger sensitivities to detect temporal changes for the tonic tone than for the dominant tone, even if the dominant tone directly follows the tonic in the tonal hierarchy. The difference between tonal functions was also observed for the response bias, but both tonal functions created a tendency to respond "No, there was no change" (a positive bias), which was stronger for the tonic than the dominant. Over Experiments 1 and 2, the difference in tested positions of the tonal hierarchy was mainly reflected for the response bias and, notably, it was the strongest for the opposition between tonic and leading tone. ${ }^{3}$ Together with musical priming data using intonation and asynchrony judgments (see, e.g., Bharucha \& Stoeckig, 1987; Tillmann \& Bharucha, 2002), this finding suggests that response biases reflect a more general, taskindependent phenomenon linked to contextual tonal expectations, and it further shows that the extent of the response bias depends on the strength of tonal manipulation.

In contrast to response bias, listeners' sensitivities $\left(d^{\prime}\right)$ did not reflect the ranking of the four tones in the tonal hierarchy (i.e., tonic $>$ dominant $>$ mediant $>$ leading tone), but only the difference between higher versus lower tonal stability. This result might be linked to the betweengroups comparisons, whereas within-participants comparisons might allow a ranking to emerge that reflects the tonal hierarchy. Note that the tonic is at the top of the hierarchy and is the most referential member of a key. On the basis of mere exposure to musical pieces in everyday life, the tonic might assume the role of a cognitive reference point to which other musical events are anchored and referred to (Bharucha, 1984; Krumhans1, 1979). Recent harmonic priming data confirmed the special status of the tonic: Even if the response time pattern reflected the ranking of the chords in the harmonic hierarchy (i.e., processing was the fastest for the tonic, followed by the dominant and then the subdominant), the comparison with neutral baseline contexts (i.e., chord sequences without established key) revealed that only the tonic chord was facilitated in processing (Tillmann, Janata, Birk, \& Bharucha, 2003, 2007). The subdominant chord (i.e., third position in the harmonic hierarchy) resulted in inhibition, whereas the dominant (i.e., second position) was situated at baseline level. In our present study (even if targets were tones), the absence of detailed ranking might also reflect that increased temporal discrimination is related to the benefit of processing, which is restricted to tonics.

\section{GENERAL DISCUSSION}

Our present study investigated whether a tone's tonal function influences the detection of a temporal change that is disrupting a sequence's regularity. Sequences consisted of six musical events presented in isochrony (or not): Three chords instilled a tonal context and were followed by a tone (repeated three times) with different tonal functions. Discrimination performance (as measured by $d^{\prime}$ ) showed an influence of tonal function on temporal change detection: Performance was better for the tonic 
tone (having the most important tonal function in the key) than for the unstable leading tone, the less stable mediant tone, and even the stable dominant tone.

Since the task required participants only to focus on the temporal regularity (without being informed about tonal manipulations), the influence of tonal function on temporal processing points to the automatic processing of tonal functions. This finding provides converging evidence with data for sung music: The tonal function of the chord, on which a syllable or a word was sung, influenced phoneme discrimination (Bigand, Tillmann, Poulin, D’Adamo, \& Madurell, 2001) and lexical decision (Poulin-Charronnat, Bigand, Madurell, \& Peereman, 2005). The data for sung music have been interpreted in terms of interactive processes between musical structures and language, an outcome thus contributing to the debate of interaction versus independence in music and language processing. Similarly, our finding suggests that the processing of tonal structures interacts with the processing of temporal information at some stage of processing. It integrates into the ongoing debate in music cognition research about whether listeners process structural regularities on pitch and time dimensions independently (e.g., Palmer \& Krumhansl, 1987a, 1987b; Peretz, 1990, 1996; Peretz \& Kolinsky, 1993; Peretz \& Morais, 1980; Piccirilli, Sciarma, \& Luzzi, 2000; Wilson, Pressing, \& Wales, 2002) or in interaction (e.g., Bigand, 1997; Bigand \& Pineau, 1997; Boltz, 1989a, 1989b, 1991, 1993, 1995, 1998; Jones \& Boltz, 1989; Jones, Boltz, \& Klein, 1993; Schmuckler \& Boltz, 1994). Our finding shows that the processing of the temporal dimension is influenced by the pitch dimension (i.e., the tones' tonal functions). However, it cannot further specify whether differences in tonal functions are modified by temporal positions (on time vs. early/late), since $d^{\prime}$ calculations integrate on-time trials and early/late trials into the same parameter.

The influence of tonal functions on temporal processing has also been reported for the judgment of a temporal feature of a chord (Tillmann \& Bharucha, 2002). Participants were required to judge whether all four tones of a target were played simultaneously or whether one tone was slightly delayed (i.e., temporal asynchrony detection). The target (e.g., C Major) was preceded by either a harmonically related chord belonging to the same key (e.g., G Major), or an unrelated chord belonging to a distant key (e.g., F\# Major). In contrast to our present data, temporal asynchrony detection (as measured by $d^{\prime}$ ) was better for unrelated, unstable targets than for related ones. This difference in facilitation pattern might be due to the difference between simultaneous and sequential temporal processing, to the opposition between in-key and out-of-key events versus in-key events only, as well as to the length of the tonal contexts (i.e., one chord vs. four musical events). Further investigations are thus needed, notably to understand how tonal and temporal processing interacts in the perception of more realistic musical material (i.e., sequences with melodic lines as well as simultaneously occurring tones). Temporal perception of sequentially occurring events in musical sequences is influenced by the overall phrase structure of the piece (Repp, 1992, 1998b, 1998c, 1999), but it remains to be shown how the detec- tion of temporal deviations of (sequentially and simultaneously presented) musical events is influenced by their tonal function.

In addition to increased sensitivity for tonics, listeners' sensitivities were increased for positive changes (i.e., the tobe-detected tone was played later than expected in the regularity of the context) in comparison with negative changes. Asymmetric patterns between "earlier" and "later" trials have been observed with different tasks and experimental materials (see, e.g., Jones et al., 2006; McAuley \& Kidd, 1998; Schmuckler \& Boltz, 1994; Tillmann \& LebrunGuillaud, 2006). Our effect of direction of temporal change is in agreement with Hibi (1983; reported by Friberg \& Sundberg, 1995), who observed better temporal change detection thresholds (i.e., just-noticeable differences) when the displacements were in a forward direction (positive change) than in a backward direction (negative change).

The effect of temporal change direction on detection performance can be integrated in oscillator-based approaches of time perception (Jones \& Boltz, 1989; Large \& Jones, 1999; McAuley \& Jones, 2003). According to this view, listening to regular sequences leads to the establishment of internal oscillators resonating in phase with the external stimulus. Linked to these oscillators, listeners' attention is not equally distributed over time, but follows attentional cycles. Periodically, an attentional peak coincides with the moment of occurrence of an event, leading to more accurate perception and production (e.g., Jones et al., 2002). In our material, the first four contextual events establish that the periodicities of internal oscillators and temporal change detection would be influenced by the difference between external periodicities (in the stimulus) and internal periodicities (based on the oscillators). In negative change trials, the to-be-detected event is played before the peak of the attentional pulse: This might disturb the currently running oscillator and decrease accuracy in evaluating the sequence's regularity. In positive change trials, two cues linked to the internal oscillators might increase detection performance (in contrast to one cue for negative change trials). (1) At the expected time (i.e., at the peak of the attentional pulse), the expected event is missing, and (2) an event appeared at a later point in time. ${ }^{4}$

A further, more music-specific mechanism might have led to the advantage of positive over negative trials: Positive and negative trials create a long-short interval pattern and a short-long interval pattern, respectively. Since listeners have knowledge about expressive musical performance, which often uses decrease in tempo at the end of musical sections (e.g., Repp, 1998a, 1998b; Todd, 1985), listeners might expect a final interval lengthening also for the present material. Consequently, the short-long pattern fits this expectation, rendering its detection more difficult, whereas the long-short pattern violates the expectation, thus being detected better.

Finally, the influence of direction of change on response bias might be integrated into the scalar expectancy theory, a model of timing that includes decision processes, next to an internal clock and memory (Droit-Volet \& Wearden, 2003; Wearden, 2004). Data on duration judgments have shown asymmetrical gradients between durations being 
longer versus shorter than the standard (see Wearden, 2004, for a review). This model has been tested for the perception of single intervals, but the involved decisional processes might also apply to temporal sequence perception, as is the case in our present study.

The overall outcome of our study shows that listeners (even musically inexperienced ones) differentiate between fine differences in tonal degrees and that these processed tonal functions influence discrimination performance for temporal features in the sequences. The paradigm introduced an indirect investigation method to analyze listeners' knowledge about tonal functions and relations. Participants were not directly asked to judge the tonal structures of the sequences, but the tonal relations influenced discrimination performance in the temporal task. Indirect investigation methods provide powerful tools to reveal implicit knowledge, most particularly for patients with impaired explicit knowledge. This advantage of implicit processing is an established finding in neuropsychological research, which has been observed, among others, for face perception (see, e.g., Young, Hellawell, \& de Haan, 1988), language processing (e.g., Mimura, Goodglass, \& Milberg, 1996), and more recently, music perception (Tillmann, Peretz, Bigand, $\&$ Gosselin, 2007). The experimental paradigm introduced by our study, which combines temporal and tonal processing, will allow us to further investigate implicit tonal knowledge in amusic patients and congenital amusics. ${ }^{5}$ Although impaired in pitch change detection, congenital amusics succeed in temporal change detection (Hyde \& Peretz, 2004). Our task should allow testing of whether congenital amusics' sparse implicit tonal knowledge (revealed by the musical priming paradigm; see Tillmann, Peretz, et al., 2007) is sufficiently elaborated to process the different tonal degrees. Of particular interest would be the opposition between tonic and leading tone, which resulted in a strong (and for 40-msec trials, inverse) response bias for healthy listeners. Since congenital amusics show deficits in explicit music processing (e.g., Foxton, Dean, Gee, Peretz, \& Griffiths, 2004; Peretz, 2001; Peretz et al., 2002), tonal function should influence discrimination performance, but not response bias.

\section{AUTHOR NOTE}

This research was supported in part by the grant program "Emergence" of the French Rhône-Alpes Region and a Junior Research Team grant by the French Ministry of Research. Correspondence concerning this article should be addressed to B. Tillmann, Université Claude Bernard Lyon I, CNRS-UMR 5020, Neurosciences, Comportement, Cognition, 50 Av. Tony Garnier, F-69366 Lyon Cedex 07, France (e-mail: barbara.tillmann@olfac.univ-lyon1.fr).

\section{REFERENCES}

Barnes, R., \& Jones, M. R. (2000). Expectancy, attention, and time. Cognitive Psychology, 41, 254-311.

BharUCHA, J. J. (1984). Anchoring effects in music: The resolution of dissonance. Cognitive Psychology, 16, 485-518.

Bharucha, J. J., \& Pryor, J. H. (1986). Disrupting the isochrony underlying rhythm: An asymmetry in discrimination. Perception \& Psychophysics, 40, 137-141.

Bharucha, J. J., \& Stoeckig, K. (1987). Priming of chords: Spreading activation or overlapping frequency spectra? Perception \& Psychophysics, 41, 519-524.
Bigand, E. (1997). Perceiving musical stability: The effect of tonal structure, rhythm, and musical expertise. Journal of Experimental Psychology: Human Perception \& Performance, 23, 808-822.

Bigand, E., \& PARncutt, R. (1999). Perceiving musical tension in long chord sequences. Psychological Research, 62, 237-254.

Bigand, E., \& Pineau, M. (1997). Global context effects on musical expectancy. Perception \& Psychophysics, 59, 1098-1107.

Bigand, E., Poulin, B., Tillmann, B., \& D’Adamo, D. (2003). Cognitive versus sensory components in harmonic priming effects. Journal of Experimental Psychology: Human Perception \& Performance, 29, 159-171.

Bigand, E., \& Poulin-Charronnat, B. (2006). Are we "experienced listeners"? A review of the musical capacities that do not depend on formal musical training. Cognition, 100, 100-130.

Bigand, E., Tillmann, B., Poulin, B., D’Adamo, D. A., Madurell, F. (2001). The effect of harmonic context on phoneme monitoring in vocal music. Cognition, 81, B11-B20.

Boltz, M. G. (1989a). Perceiving the end: Effects of tonal relationships on melodic completion. Journal of Experimental Psychology: Human Perception \& Performance, 15, 749-761.

Boltz, M. G. (1989b). Rhythm and "good endings": Effects of temporal structure on tonality judgments. Perception \& Psychophysics, 46, 9-17.

BoLTZ, M. G. (1991). Some structural determinants of melody recall. Memory \& Cognition, 19, 239-251.

Boltz, M. G. (1993). The generation of temporal and melodic expectancies during musical listening. Perception \& Psychophysics, 53, 585-600.

Boltz, M. G. (1995). Effects of event structure on retrospective duration judgments. Perception \& Psychophysics, 57, 1080-1096.

Boltz, M. G. (1998). Tempo discrimination of musical patterns: Effects due to pitch and rhythmic structure. Perception \& Psychophysics, 60, 1357-1373.

Cohen, J., MacWhinney, B., Flatt, M., \& Provost, J. (1993). PsyScope: An interactive graphic system for designing and controlling experiments in the psychology laboratory using Macintosh computers. Behavior Research Methods, Instruments, \& Computers, 25, 257-271.

DraKe, C. (1993). Reproduction of musical rhythms by children, adult musicians, and adult nonmusicians. Perception \& Psychophysics, 53, 25-33.

Drake, C., \& Botte, M.-C. (1993). Tempo sensitivity in auditory sequences: Evidence for a multiple-look model. Perception \& Psychophysics, 54, 277-286.

Drake, C., Penel, A., \& Bigand, E. (2000). Tapping in time with mechanically and expressively performed music. Music Perception, 18, $1-23$.

Droit-Volet, S., \& Wearden, J. (2003). Les modèles d'horloge interne en psychologie du temps. L'Année Psychologique, 104, 617-654.

Ehrlé, N., \& SAMSON, S. (2005). Auditory discrimination of anisochrony: Influence of the tempo and musical backgrounds of listeners. Brain \& Cognition, 58, 133-147.

Essens, P. J., \& Povel, D.-J. (1985). Metrical and nonmetrical representations of temporal patterns. Perception \& Psychophysics, 37, 1-7.

Foxton, J. M., Dean, J. L., Gee, R., Peretz, I., \& Griffiths, T. D. (2004). Characterization of deficits in pitch perception underlying "tone deafness." Brain, 127, 801-810.

Fraisse, P. (1974). Memory of drawings and sentences depending on the duration of presentation. L'Année Psychologique, 74, 145-156.

FrancÈs, R. (1958). La perception de la musique (2nd ed.). Paris: PUF.

Friberg, A., \& SundberG, J. (1995). Time discrimination in a monotonic, isochronous sequence. Journal of the Acoustical Society of America, 98, 2524-2531.

Halpern, A. R., \& Darwin, C. J. (1982). Duration discrimination in a series of rhythmic events. Perception \& Psychophysics, 31, 86-89.

HÉBert, S., \& Cuddy, L. L. (2002). Detection of metric structure in auditory figural patterns. Perception \& Psychophysics, 64, 909-918.

Hébert, S., Peretz, I., \& Gagnon, L. (1995). Perceiving the tonal ending of tune excerpts: The roles of pre-existing representation and musical expertise. Canadian Journal of Experimental Psychology, 49, 193-209.

HIBI, S. (1983). Rhythm perception in repetitive sound sequence. Journal of the Acoustical Society of Japan, 4, 83-95.

Hirsh, I. J., Monahan, C. B., Grant, K. W., \& Singh, P. G. (1990). 
Studies in auditory timing: 1 . Simple patterns. Perception \& Psychophysics, 47, 215-226.

Hyde, K. L., \& Peretz, I. (2004). Brains that are out of tune but in time. Psychological Science, 15, 356-360.

Jones, M. R. (1976). Time, our lost dimension: Toward a new theory of perception, attention, and memory. Psychological Review, 83, 323-355.

Jones, M. R., \& Boltz, M. G. (1989). Dynamic attending and responses to time. Psychological Review, 96, 459-491.

Jones, M. R., Boltz, M. G., \& Klein, J. M. (1993). Expected endings and judged duration. Memory \& Cognition, 21, 646-665.

Jones, M. R., Johnston, H. M., \& Puente, J. (2006). Effects of auditory pattern structure on anticipatory and reactive attending. Cognitive Psychology, 53, 59-96.

Jones, M. R., Moynihan, H., MacKenzie, N., \& Puente, J. (2002). Temporal aspects of stimulus-driven attending in dynamic arrays. Psychological Science, 13, 313-319.

KrumhanSL, C. L. (1979). The psychological representation of musical pitch in a tonal context. Cognitive Psychology, 11, 346-374.

Krumhansl, C. L. (1990). Cognitive foundations of musical pitch. Oxford: Oxford University Press.

Krumhansl, C. L. (2000). Rhythm and pitch in music cognition. Psychological Bulletin, 126, 159-179.

Krumhansl, C. L., \& Kessler, E. (1982). Tracing the dynamic changes in perceiving tonal organization in a spatial representation of musical keys. Psychological Review, 89, 334-368.

Large, E. W., \& Jones, M. R. (1999). The dynamics of attending: How people track time-varying events. Psychological Review, 106, 119159.

Longuet-Higgins, H. C., \& LeE, C. S. (1984). The rhythmic interpretation of monophonic music. Music Perception, 1, 424-441.

Macmillan, N. A., \& Creelman, C. D. (1991). Detection theory: A user's guide. Cambridge: Cambridge University Press.

McAuley, J. D., \& Jones, M. R. (2003). Modeling effects of rhythmic context on perceived duration: A comparison of interval and entrainment approaches to short-interval timing. Journal of Experimental Psychology: Human Perception \& Performance, 29, 1102-1125.

McAuley, J. D., \& KIDD, G. R. (1998). Effect of deviations from temporal expectations on tempo discrimination of isochronous tone sequences. Journal of Experimental Psychology: Human Perception \& Performance, 24, 1786-1800.

Mimura, M., Goodglass, H., \& Milberg, W. (1996). Preserved semantic priming effect in alexia. Brain \& Language, 54, 434-446.

Palmer, C., \& Krumhansl, C. L. (1987a). Independent temporal and pitch structures in determination of musical phrase. Journal of Experimental Psychology: Human Perception \& Performance, 13, 116-126.

Palmer, C., \& Krumhansl, C. L. (1987b). Pitch and temporal contributions to musical phrase perception: Effects of harmony, performance timing, and familiarity. Perception \& Psychophysics, 41, 505-518.

Patel, A. D., Iversen, J. R., Chen, Y., \& RePP, B. H. (2005). The influence of metricality and modality on synchronization with a beat. Experimental Brain Research, 163, 226-238.

PERETZ, I. (1990). Processing of local and global musical information in unilateral brain-damaged patients. Brain, 113, 1185-1205.

Peretz, I. (1996). Can we lose memories for music? The case of music agnosia in a nonmusician. Journal of Cognitive Neuroscience, 8, 481-496.

Peretz, I. (2001). Brain specialization for music: New evidence from congenital amusia. Annals of the New York Academy of Sciences, 930, 153-165.

Peretz, I., Ayotte, J., Zatorre, R. J., Mehler, J., Ahad, P., Penhune, V. B., \& Jutras, B. (2002). Congenital amusia: A disorder of finegrained pitch discrimination. Neuron, 33, 185-191.

Peretz, I., \& Kolinsky, R. (1993). Boundaries of separability between melody and rhythm in music discrimination: A neuropsychological perspective. Quarterly Journal of Experimental Psychology, 46A, 301-325.

Peretz, I., \& Morais, J. (1980). Modes of processing melodies and ear asymmetry in non-musicians. Neuropsychologia, 18, 477-489.

Piccirilli, M., Sciarma, T., \& Luzzi, S. (2000). Modularity of music: Evidence from a case of pure amusia. Journal of Neurology, Neurosurgery \& Psychiatry, 69, 541-545.

Poulin-Charronnat, B., Bigand, E., Madurell, F., \& Peereman, R.
(2005). Musical structure modulates semantic priming in vocal music. Cognition, 94, B67-B78.

PoveL, D.-J. (1981). Internal representation of simple temporal patterns. Journal of Experimental Psychology: Human Perception \& Performance, 7, 3-18.

Povel, D.-J., \& Essens, P. [J.] (1985). Perception of temporal patterns. Music Perception, 2, 411-440.

RepP, B. H. (1992). Probing the cognitive representation of musical time: Structural constraints on the perception of timing. Cognition, 44, 241-281.

REPP, B. H. (1998a). A microcosm of musical expression. I. Quantitative analysis of pianists' timing in the initial measures of Chopin's Etude in E major. Journal of the Acoustical Society of America, 104, $1085-1100$

REPP, B. H. (1998b). Obligatory "expectations" of expressive timing induced by perception of musical structure. Psychological Research, 61, 33-43.

RePP, B. H. (1998c). Variations on a theme by Chopin: Relations between perception and production of timing in music. Journal of Experimental Psychology: Human Perception \& Performance, 24, 791-811.

Repp, B. H. (1999). Detecting deviations from metronomic timing in music: Effects of perceptual structure on the mental timekeeper. Perception \& Psychophysics, 61, 529-548.

SCHMUCKLER, M. A., \& Boltz, M. G. (1994). Harmonic and rhythmic influences on musical expectancy. Perception \& Psychophysics, 56, 313-325.

Tillmann, B. (2005). Implicit investigations of tonal knowledge in nonmusician listeners. In G. Avanzini, L. Lopez, S. Koelsch, \& M. Majno (Eds.), The neurosciences and music II: From perception to performance (Annals of the New York Academy of Sciences, Vol. 1060, pp. 100-110). New York: New York Academy of Sciences.

Tillmann, B., \& Bharucha, J. J. (2002). Effect of harmonic relatedness on the detection of temporal asynchronies. Perception \& Psychophysics, 64, 640-649.

Tillmann, B., Bharucha, J. J., \& Bigand, E. (2000). Implicit learning of tonality: A self-organizing approach. Psychological Review, 107, 885-913.

Tillmann, B., \& Bigand, E. (2001). Global relatedness effect in normal and scrambled chord sequences. Journal of Experimental Psychology: Human Perception \& Performance, 27, 1185-1196.

Tillmann, B., Bigand, E., Escoffier, N., \& Lalitte, P. (2006). The influence of musical relatedness on timbre discrimination. European Journal of Cognitive Psychology, 18, 343-358.

Tillmann, B., Bigand, E., \& Madurell, F. (1998). Influence of global and local structures on the solution of musical puzzles, Psychological Research, 61, 157-174.

Tillmann, B., Janata, P., Birk, J., \& Bharucha, J. J. (2003). The costs and benefits of tonal centers for chord processing. Journal of Experimental Psychology: Human Perception \& Performance, 29, 470-482.

Tillmann, B., Janata, P., Birk, J., \& Bharucha, J. J. (2007). Tonal centers and expectancy: Facilitation or inhibition of chords at the top of the harmonic hierarchy? Manuscript submitted for publication.

Tillmann, B., \& Lebrun-Guillaud, G. (2006). Influence of tonal and temporal expectations on chord processing and on completion judgments of chord sequences. Psychological Research, 70, 345-358.

Tillmann, B., Peretz, I., Bigand, E., \& Gosselin, N. (2007). Harmonic priming in an amusic patient: The power of implicit tasks. Cognitive Neuropsychology, 24, 603-622.

TodD, N. P. M. (1985). A model of expressive timing in tonal music. Music Perception, 3, 33-53.

Wearden, J. H. (2004). Decision processes in models of timing. Acta Neurobiologiae Experimentalis, 64, 303-317.

Wilson, S. J., Pressing, J. L., \& Wales, R. J. (2002). Modelling rhythmic function in a musician post-stroke. Neuropsychologia, 40, 1494-1505.

Yee, W., Holleran, S., \& Jones, M. R. (1994). Sensitivity to event timing in regular and irregular sequences: Influences of musical skill. Perception \& Psychophysics, 56, 461-471.

Young, A. W., Hellawell, D., \& De HaAn, E. H. F. (1988). Crossdomain semantic priming in normal subjects and a prosopagnosic patient. Quarterly Journal of Experimental Psychology, 40A, 561-580. 


\section{NOTES}

1. Roman numbers and tonal degrees are defined in reference to the diatonic scale (e.g., C, D, E, F, G, A, B), notably the position of the corresponding tone in this scale (with the tonic being the first tone [C], the dominant being the fifth tone $[\mathrm{G}]$, the subdominant being the fourth tone $[\mathrm{F}]$, etc.).

2. The correction of the $d^{\prime}$ and $c$ measures used the formulas FA $=$ $1 / 2 n$ and hits $=1-1 / 2 n(n=$ number of stimuli) for cases without false alarms or the maximum number of hits (Macmillan \& Creelman, 1991).

3. To compare $d^{\prime}$ and $c$ data over the three tonal oppositions (for 40-msec changes only), analyses with type of nontonic tone (leading tone/ mediant/dominant) and musical expertise (inexperienced/moderately experienced) as between-participants factors and tonal function (strong/ weak) and direction of temporal change (negative/positive) as withinparticipants factors were realized. As observed in Experiment 1, the interaction between type of nontonic tone and tonal function was significant only for $c\left[F(2,91)=3.57, M S_{\mathrm{e}}=0.06, p<.05\right]$.

4. An alternative explanation (possibly adding up with processes linked to internal oscillators) might be linked to acoustic characteristics of positive versus negative changes. Due to the resonance of the preceding tone, the onset of the displaced tone is more salient for positive changes (i.e., the tone is played later) than for negative changes (i.e., the tone is played earlier). In negative-change trials, the resonance of the previous tone is still sounding and the ratio between the minimal amplitude (i.e., offset) and the maximal amplitude (i.e., onset) is less important than that in positive-change trials.

5. Congenital amusia (or tone deafness) refers to a lifelong musical disorder that cannot be explained by hearing loss, brain lesions, or cognitive and social deficits.

(Manuscript received November 7, 2006; revision accepted for publication June 6,2007 .) 